\title{
Role of Defect Interaction in Boundary Mobility and Cation Diffusivity of $\mathrm{CeO}_{2}$
}

\author{
Pei-Lin Chen* and I-Wei Chen*
}

Department of Materials Science and Engineering, University of Michigan, Ann Arbor, Michigan 48109-2136

Grain boundary mobility of $\mathrm{CeO}_{2}$ containing $0.1 \%$ and $1.0 \%$ trivalent dopant cations (Sc, Yb, Y, Gd, and La, in order of increasing ionic radius) has been measured. At the lower dopant concentration (intrinsic regime), mobility is controlled by grain boundary diffusion of host cations, whereas at the higher dopant concentration (extrinsic regime), mobility is controlled by solute drag through the lattice. The effect of trivalent dopants is closely associated with their ability to provide and to interact with oxygen vacancies. Evidence consistent with an interstitial mechanism for cation diffusion has been found which is remarkably affected by the presence of oxygen vacancies. Ce diffusion is enhanced by free oxygen vacancies in the system, while dopant diffusion is suppressed if a dopantassociated oxygen vacancy is not present. A bare Sc cation, however, appears to be a fast-diffusing species, due to its highly distorted local environment, while $Y$ at $1.0 \%$ emerges as the most effective grain growth suppressant.

\section{Introduction}

$\mathrm{C}$ ONTROL of grain boundary mobility is often called for in attaining desirable sintering characteristics, microstructure, and deformation behavior in high-temperature ceramics. ${ }^{1}$ Cation solutes are expected to influence grain boundary mobility via solute drag and alteration of diffusivity. Systematic investigation of this subject, however, has been lacking. In highly stoichiometric ceramics, e.g., $\mathrm{Al}_{2} \mathrm{O}_{3}$, solubility of aliovalent solute is very low, typically less than $100 \mathrm{ppm}^{2}$ This places a severe limitation on the type and composition range of the solutes that can be systematically studied in such ceramics. In addition, the effect of unintended residual impurity on grain boundary mobility is difficult to isolate from that of the dopant. Recently, we have shown ${ }^{3}$ that in a nonstoichiometric oxide, $\mathrm{Zr}_{0.88} \mathrm{Ce}_{0.12} \mathrm{O}_{2}(12 \mathrm{Ce}-\mathrm{TZP})$, grain boundary mobility can be precisely controlled by systematically applying the solute drag concept. The present work focuses on a similar oxide in the fluorite structural family, $\mathrm{CeO}_{2}$, to elucidate the size effect of trivalent cation solutes on grain boundary mobility.

$\mathrm{CeO}_{2}$ has a cubic fluorite structure which can incorporate many cations into the lattice. When a trivalent cation dopant is present, oxygen vacancies are created for charge compensation. Since $\mathrm{Ce}^{4+}$ can readily reduce itself to $\mathrm{Ce}^{3+}$, considerable oxygen vacancies are also present in undoped ceria. Thus, oxygen diffusion is fast and cation diffusion is always the rate-controlling step for grain boundary migration at all compositions. Previous research on undoped and doped $\mathrm{CeO}_{2}$ has provided information on the concentration of oxygen vacancy, ${ }^{4-6}$ the charge transfer mechanism between $\mathrm{Ce}^{3+}$ and $\mathrm{Ce}^{4+}, 6$ and the

Y.-M. Chiang-contributing editor

Manuscript No. 193817. Received February 18, 1994; approved May 6. 1994

Supported by the U.S. Department of Energy (BES) under Grant No. DE-FG02-87ER45302.

${ }^{*}$ Member, American Ceramic Society. size dependence of oxygen vacancy association with trivalent dopants. ${ }^{7-8}$ This background suggests that $\mathrm{CeO}_{2}$ would be an excellent model for nonstoichiometric oxide for investigating the solute effect on grain boundary mobility. It should be noted, however, that no data on cation diffusivity in $\mathrm{CeO}_{2}$ are currently available, to the best of our knowledge. No previous data on grain boundary mobility exist, either. Indeed, fully dense $\mathrm{CeO}_{2}$ has not been obtained until recently."

Trivalent cation dopants $\left(\mathrm{D}^{3+}\right)$ studied here are $\mathrm{Sc}, \mathrm{Yb}, \mathrm{Y}$, $\mathrm{Gd}$, and $\mathrm{La}$, in order of increasing ionic size. Data of solubility and lattice constants of these $\mathrm{CeO}_{2}-\mathrm{M}_{2} \mathrm{O}_{3}$ systems are available in the literature, ${ }^{10-14}$ from which Vegard's slopes (on the basis of cation percent) have been calculated and summarized in Table I. Also listed in the Table are Shannon's radii. ${ }^{14}$ Note that $\mathrm{Ce}^{4+}$, with an ionic radius of $0.97 \AA$, is placed between $\mathrm{Yb}^{3+}$ and $\mathrm{Y}^{3+}$. Thus, our choice of dopants covers a rather broad size range bracketing the host cation size. To select the dopant concentration, we refer to undoped $\mathrm{CeO}_{2}$ in air and its $\mathrm{Ce}^{3+}$ concentration ( $\left[\mathrm{Ce}^{3+}\right]$ on the basis of cation fraction). The data from the literature ${ }^{5}$ are shown in Fig. 1 for the temperature range between $1270^{\circ}$ and $1470^{\circ} \mathrm{C}$. Referring to this figure, we have chosen $0.1 \%$ as the dopant concentration $\left(\left[\mathrm{D}^{3+}\right]\right)$ that is within the intrinsic regime $\left(\left[\mathrm{D}^{3+}\right]<\left[\mathrm{Ce}^{3+}\right]\right)$, and $1.0 \%$ as the dopant concentration within the extrinsic regime $\left(\left[\mathrm{D}^{3+}\right]>\left[\mathrm{Ce}^{3+}\right]\right)$. In addition, undoped ceria is studied under several oxygen partial pressures to examine the effect of $\left[\mathrm{Ce}^{3+}\right]$ or, equivalently, $\left[V_{0}\right]$, the oxygen vacancy concentration.

\section{Experimental Procedure}

Ultrafine highly reactive $\mathrm{CeO}_{2}$ powders prepared by a homogeneous precipitation method as described in our previous paper $^{9}$ were used as starting powders, to which dopants were added in the form of nitrates. Dopant concentrations were fixed at $0.1 \%$ or $1.0 \%$ of the total cations. To avoid $\mathrm{SiO}_{2}$ contamination, powder processing was conducted using plastic ware only.

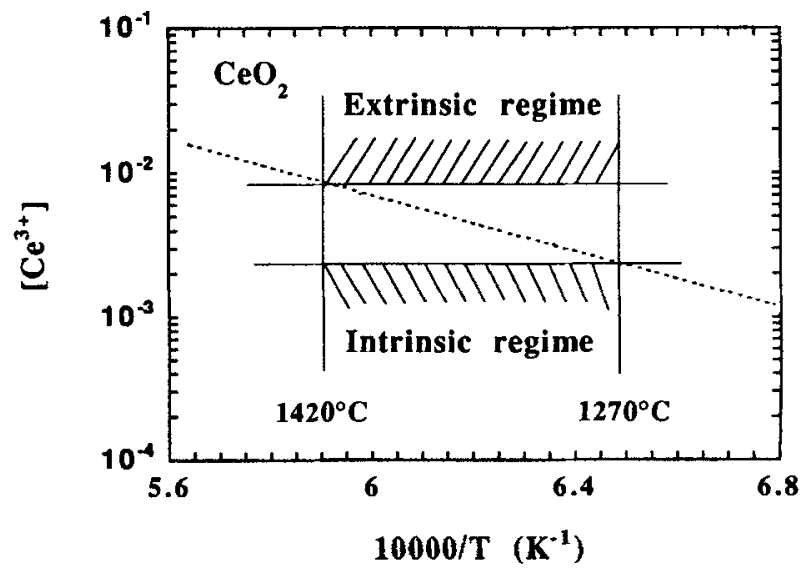

Fig. 1. Defect concentration, $\left[\mathrm{Ce}^{3+}\right]$, vs reciprocal temperature for undoped $\mathrm{CeO}_{2}$. (Data from Ref. 5.) Intrinsic and extrinsic regimes for dopant concentrations are shown for $1270^{\circ}$ to $1420^{\circ} \mathrm{C}$. 
Table I. Ionic Radius, Vegard's Slope, and Solubility of $\mathrm{MO}_{1.5}$ in $\mathrm{CeO}_{2}$

\begin{tabular}{|c|c|c|c|c|}
\hline & $\begin{array}{c}\text { Ionic radius* } \\
(\AA)\end{array}$ & $\begin{array}{l}\text { Vegard's slope }{ }^{\dagger} \\
\left(\times 10^{3}\right)\end{array}$ & $\begin{array}{l}\text { Solubility } \\
\left(\% \mathrm{MO}_{1.5}\right)\end{array}$ & Ref. \\
\hline $\mathrm{Sc}^{3+}$ & 0.87 & -1.0823 & $9.5\left(1750^{\circ} \mathrm{C}\right)$ & 11,12 \\
\hline $\mathrm{Yb}^{3+}$ & 0.99 & & $40\left(1400^{\circ} \mathrm{C}\right)$ & 11,13 \\
\hline $\mathrm{Y}^{3+}$ & 1.02 & -0.0402 & $\begin{array}{c}100\left(1200^{\circ} \mathrm{C}\right) \\
48.6\left(1400^{\circ} \mathrm{C}\right)\end{array}$ & $11,12,13$ \\
\hline $\mathrm{Gd}^{3+}$ & 1.053 & 0.4145 & $\begin{array}{r}100\left(1400^{\circ} \mathrm{C}\right) \\
54\left(1600^{\circ} \mathrm{C}\right)\end{array}$ & 11,13 \\
\hline $\mathrm{La}^{3+}$ & 1.16 & 1.7859 & $\begin{array}{l}61\left(1275^{\circ} \mathrm{C}\right) \\
45\left(1600^{\circ} \mathrm{C}\right)\end{array}$ & 11,13 \\
\hline
\end{tabular}

$*$ Ref. 14 .
pure $\left.\mathrm{CeO}_{2}\right)$.

$\mathrm{CeO}_{2}$ powders were first dispersed in isopropyl alcohol. A desired amount of dissolved dopant nitrate was then added. The slurry was poured through a $20-\mu \mathrm{m}$ nylon screen and dried under heat while being stirred. The dried powders were screened through a $100-\mu \mathrm{m}$ nylon screen and calcined. The powders were dry-pressed into pellets with a diameter of 10 $\mathrm{mm}$ and further isostatically pressed at $300 \mathrm{MPa}$. The green density after isostatic pressing was about $41 \%$ of the theoretical density. For sintering, a constant heating rate, $10^{\circ} \mathrm{C} / \mathrm{min}$, was used to reach the desired temperatures ranging from $1270^{\circ}$ to $1470^{\circ} \mathrm{C}$. Samples were held there from $6 \mathrm{~min}$ to $15 \mathrm{~h}$, and furnace cooled. Flowing gas was used when a controlled atmosphere was needed.

The microstructures of the sintered specimens were characterized by a scanning electron microscope (SEM) after polishing and thermal etching. The grain size was obtained by multiplying the average linear intercept length of at least 500 grains by $1.56 .{ }^{15}$ In addition, the grain diameter was used to evaluate the grain size distribution. For grain growth study, only samples with a density higher than $99 \%$ were used. Some specimens, which could be fractured intergranularly at room temperature, were also examined by $\mathrm{X}$-ray photoelectron spectroscopy for chemical analysis (ESCA). Since the ESCA signals came primarily from atoms within a distance of 1 to $2 \mathrm{~nm}$ from the surface, such measurements are representative of the near grain-boundary composition. To determine the depth distribution of the composition, argon ion beam sputtering was applied to progressively remove the near grain-boundary materials.

\section{Results}

\section{(1) Microstructure}

Selected microstructures are displayed in Fig. 2 to demonstrate the difference in grain size. Over the range of temperatures used, the smallest grain size obtained in the fully dense samples was $0.38 \mu \mathrm{m}$, as in the case of $1.0 \% \mathrm{Y}$ doping sintered at $1270^{\circ} \mathrm{C}$ for $1.2 \mathrm{~h}$ shown in Fig. 2(c). The largest grain size was $32 \mu \mathrm{m}$, as in the case of $1.0 \% \mathrm{Sc}$ doping sintered at $1420^{\circ} \mathrm{C}$ for $6 \mathrm{~h}$. The most dramatic contrast in grain size is seen at $1270^{\circ} \mathrm{C}$, with $1.0 \%$ dopants. The grain size of Sc-doped $\mathrm{CeO}_{2}$ is more than 15 times of that of $\mathrm{Y}$-doped $\mathrm{CeO}_{2}$, as shown in Figs. 2(b) and (c).

\section{(2) Grain Size Measurement}

Grain size distributions of a number of specimens have been evaluated to further ascertain that no abnormal growth has taken place. Figure 3 plots four distributions for the following specimens: undoped $\mathrm{CeO}_{2}(0.99 \mu \mathrm{m}), 1.0 \%$-Y doped $(0.38$ $\mu \mathrm{m}), 1.0 \%$-Sc doped $(18 \mu \mathrm{m})$, and $0.1 \%$-Sc doped $(1.2 \mu \mathrm{m})$. It is seen that the majority of grains have a size centered around the mean and there is no abnormal growth producing a secondary peak at larger sizes. This justifies the use of the average linear intercept length for evaluating grain growth kinetics.

Mobility of grain boundary, $M$, can be estimated from the grain growth kinetics via the following equation:

$$
\frac{\delta d}{\delta t}=M \gamma / d
$$

In the above, $d$ is the average grain size at time $t$, and $\gamma$ is the grain boundary energy. If both $M$ and $\gamma$ are independent of time, then Eq. (1) leads to the parabolic law for grain growth:

$$
d^{2}-d_{0}^{2}=2 M \gamma\left(t-t_{0}\right)
$$

where $d_{0}$ is the reference grain size at time $t_{0}$. In reality, it is also common to find nonparabolic growth with a growth exponent varying from 2 to 4 . This can be interpreted as due simply to a decreasing mobility. Despite the above variation, by plotting $d^{2}-d_{0}^{2}$ against $t-t_{0}$, the slope of the curve always gives $2 M \gamma$ according to Eq. (1). In addition, if a straight-line fit that passes through the origin is made, its slope gives the average $2 M \gamma$ over the duration of the grain growth experiment. This method is adopted here. To avoid the influence of porosity on grain boundary mobility, the time $t_{0}$ was chosen so that the sintering density had already achieved $99 \%$. Typically, $t_{0}$ is $1.2 \mathrm{~h}$ at $1270^{\circ} \mathrm{C}$ and $6 \mathrm{~min}$ at $1420^{\circ} \mathrm{C}$.

For illustration, some of the grain size data, for undoped and $1.0 \%$-doped samples sintered at $1270^{\circ} \mathrm{C}$, are plotted in Fig. 4 . Clearly the value of the slope in Fig. 4 varies over many orders of magnitude, reflecting the influence of dopants. This large variation cannot be attributed to grain boundary energy, since $\gamma$ typically varies by no more than a factor of two over a wide range of temperatures, compositions, and even grain boundary structures within the same system. Therefore, in this study we have assumed that $\gamma$ remains constant at an "estimated" value of $0.3 \mathrm{~J} / \mathrm{m}^{2}$ and evaluated the mobility from the slope directly. This practice allows us to compute the grain boundary mobility in undoped and doped $\mathrm{CeO}_{2}$ systems with reasonable certainty.

\section{(3) Undoped $\mathrm{CeO}_{2}$}

Undoped $\mathrm{CeO}_{2}$ were sintered in three atmospheres: $100 \% \mathrm{O}_{2}$, $21 \% \mathrm{O}_{2}$ (air), and $2 \% \mathrm{O}_{2}$. The mobility data for these three kinds of atmospheres at $1470^{\circ} \mathrm{C}$ are plotted in Fig. 5. They show an inverse dependence on the oxygen partial pressure $\left(P_{\mathrm{O}_{2}}\right)$. The temperature dependence of the data in air is also shown in Fig. 6 in an Arrhenius plot. The activation energy obtained is $588 \mathrm{~kJ} /$ mol, or $6.1 \mathrm{eV}$.

We caution that the above data should not be used to derive the oxygen partial pressure dependence of mobility, because in many of these experiments a short sintering time had to be used to obtain small grain sizes. Such short time was usually not enough to establish an equilibrium partial pressure. The apparent $P_{\mathrm{O}_{2}}$ dependence of Fig. 5, $M \propto P_{\mathrm{O}_{2}}{ }^{-1 / 4.8}$, is therefore not definitive, but only indicates the trend.

\section{(4) 0.1\%-Doped $\mathrm{CeO}_{2}$}

Mobility data of the doped $\mathrm{CeO}_{2}$ are compared with those of the undoped $\mathrm{CeO}_{2}$ in the same condition (air and various temperatures). Figure 7 displays the normalized mobilities of $0.1 \%$-doped $\mathrm{CeO}_{2}$ for the five dopants ordered in increasing ionic radius. The normalized mobility $\left(\tilde{M}=M_{\text {doped CeO }}\right.$ ' $M_{\text {undoped } \mathrm{CeO}_{2}}$ ) is lower than unity for smaller and larger dopants but has a maximum for intermediate-sized dopants, $\mathrm{Y}$ and $\mathrm{Gd}$. 

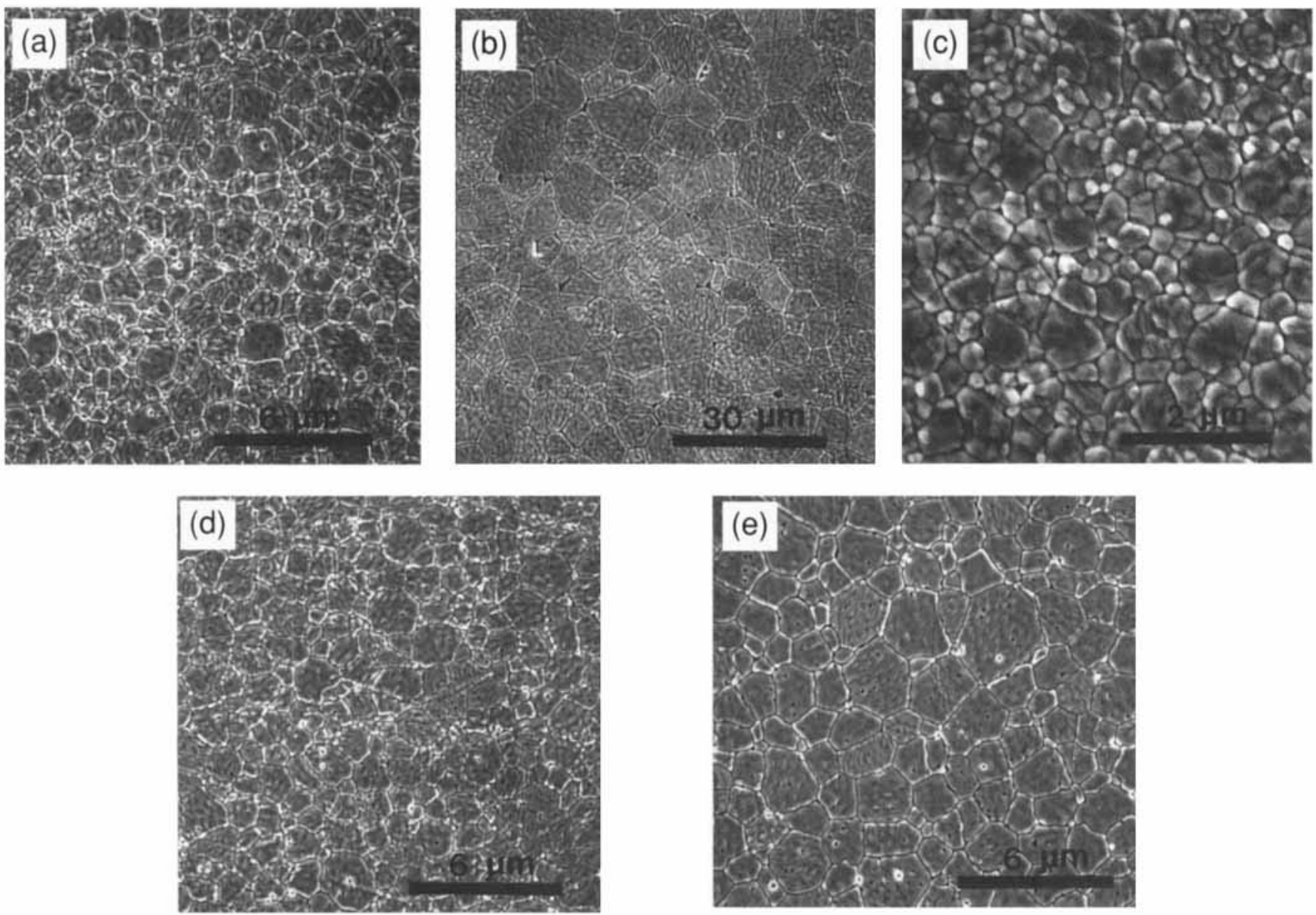

Fig. 2. Microstructures of undoped and doped $\mathrm{CeO}_{2}$ sintered at $1270^{\circ} \mathrm{C}$ for $1.2 \mathrm{~h}$; (a) $\mathrm{CeO}_{2}$, (b) $1.0 \% \mathrm{Sc}$, (c) $1.0 \% \mathrm{Y}$, (d) $0.1 \% \mathrm{Sc}$, (e) $0.1 \% \mathrm{Y}$.

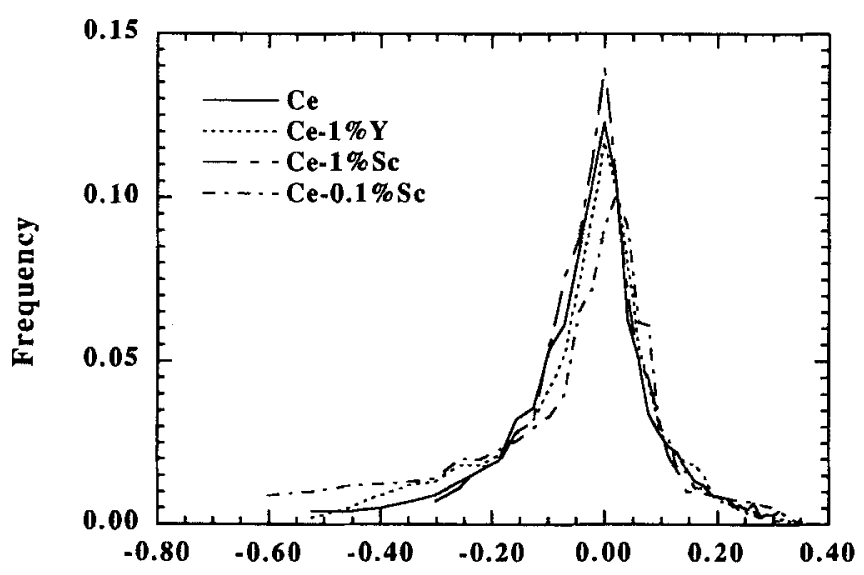

Normalized grain size

Fig. 3. Grain size distributions of undoped and doped $\mathrm{CeO}_{2}$. Grain size is normalized by mean grain size, which varies from 0.38 to $18 \mu \mathrm{m}$.

This trend is observed at all the temperatures studied in this research and is especially pronounced at low temperature. (At high temperature, e.g., $1420^{\circ} \mathrm{C}$, the normalized mobilities for $\mathrm{Y}$ and $\mathrm{Gd}$ dopants are actually smaller than unity. Thus, in this case, all the dopants studied suppress grain growth of $\mathrm{CeO}_{2}$.) The activation energies of mobility, as a function of dopant size, are shown in Fig. 8 (minimum at Gd).

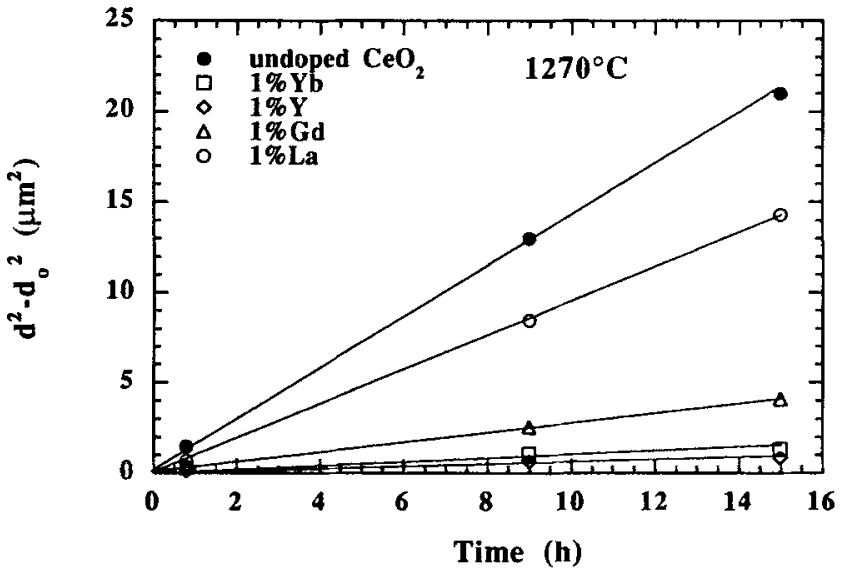

Fig. 4. Grain growth kinetics of $\mathrm{CeO}_{2}$ at $1270^{\circ} \mathrm{C}$. Dopants as indicated.

\section{(5) $1.0 \%$-Doped $\mathrm{CeO}_{2}$}

The normalized mobilities of various $1.0 \%$-doped $\mathrm{CeO}_{2}$ are shown in Fig. 9. In contrast to the feature in Fig. 7, the normalized mobility has a minimum at the intermediate-sized dopant. Moreover, with Sc being the only dopant which enhances grain growth, all other dopants show a strong suppression effect. This suppression effect becomes more pronounced at $1420^{\circ} \mathrm{C}$, although the shape of the curve remains the same at all temperatures. The activation energy of mobility as a function of dopant size is shown in Fig. 10, which has a broad maximum at $Y$. 


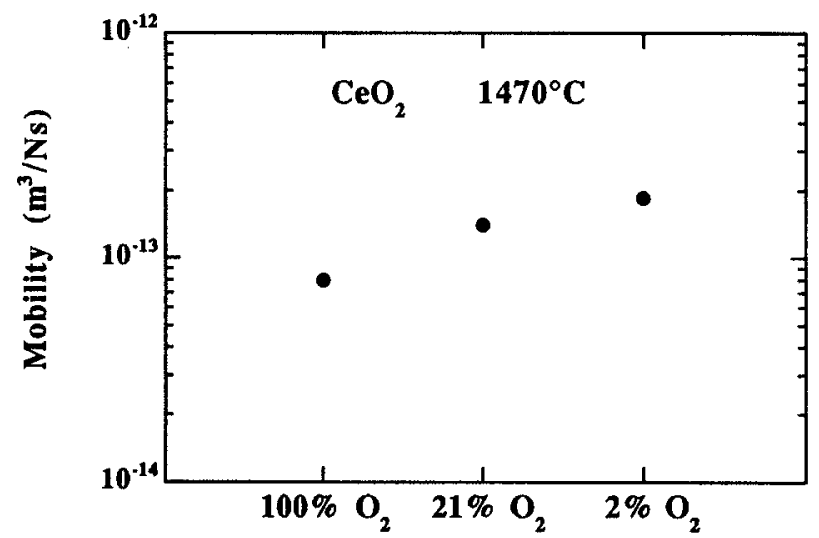

Oxygen partial pressure (\%)

Fig. 5. Grain boundary mobility of undoped $\mathrm{CeO}_{2}$ sintered at $1470^{\circ} \mathrm{C}$ in various oxygen partial pressures.

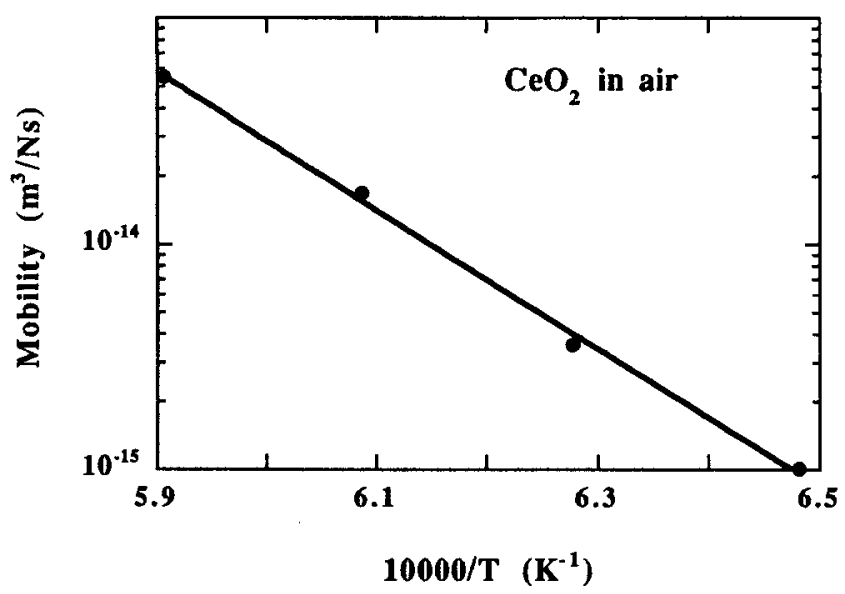

Fig. 6. Temperature dependence of grain boundary mobility for undoped $\mathrm{CeO}_{2}$.

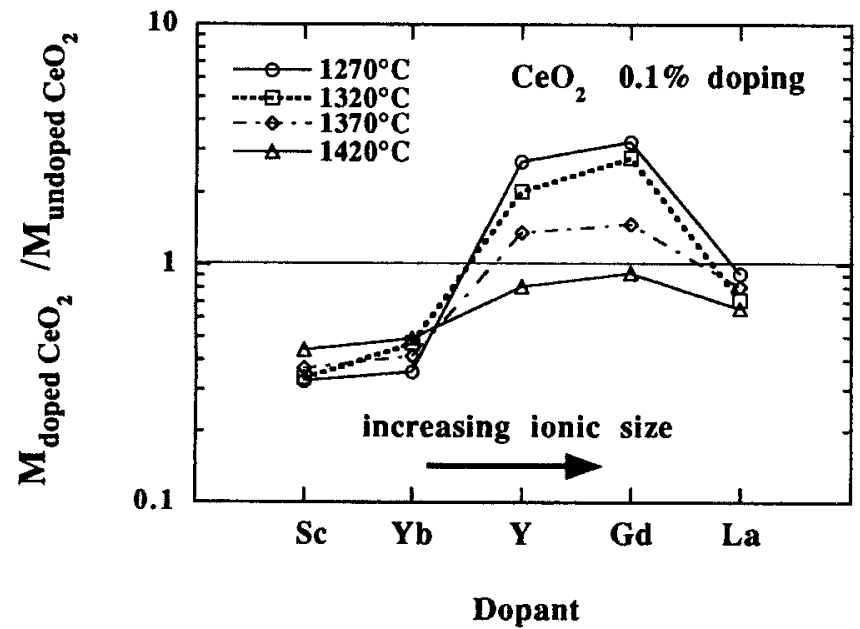

Fig. 7. Normalized grain boundary mobilities of $0.1 \%$-doped $\mathrm{CeO}_{2}$. Dopants ordered by ionic radii.

We have also used a mixture of dopants at a total concentration of $1.0 \%$ to explore any synergistic effect. This was not found for most combinations studied, but the combination of $\mathrm{Sc}$ and other dopants is an exception. For example, when $0.5 \% \mathrm{Sc}$ and $0.5 \% \mathrm{Y}$ are used together, grain boundary mobility is suppressed to a level closer to that of the $1 \%$ Y, as shown in Fig. 11.

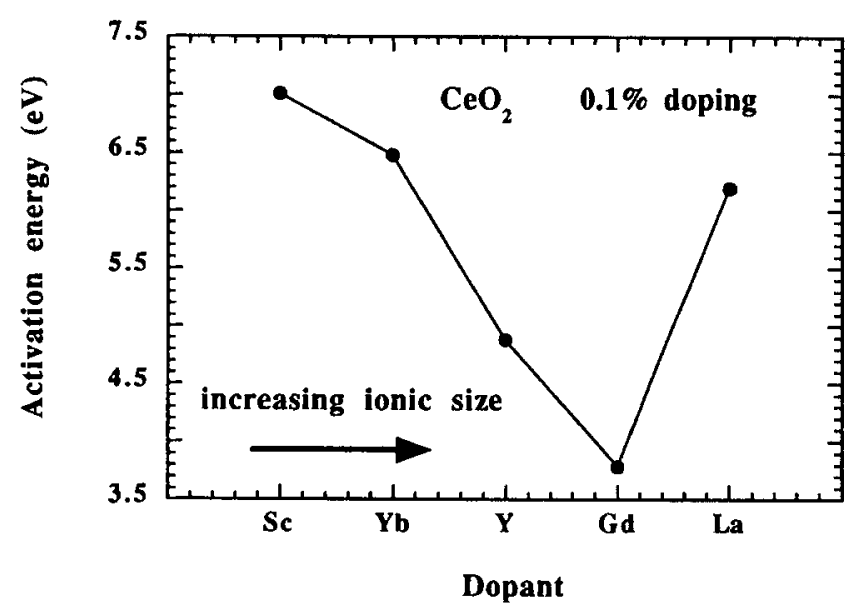

Fig. 8. Activation energy of mobility for $0.1 \%$-doped $\mathrm{CeO}_{2}$. Dopants ordered by ionic radi.
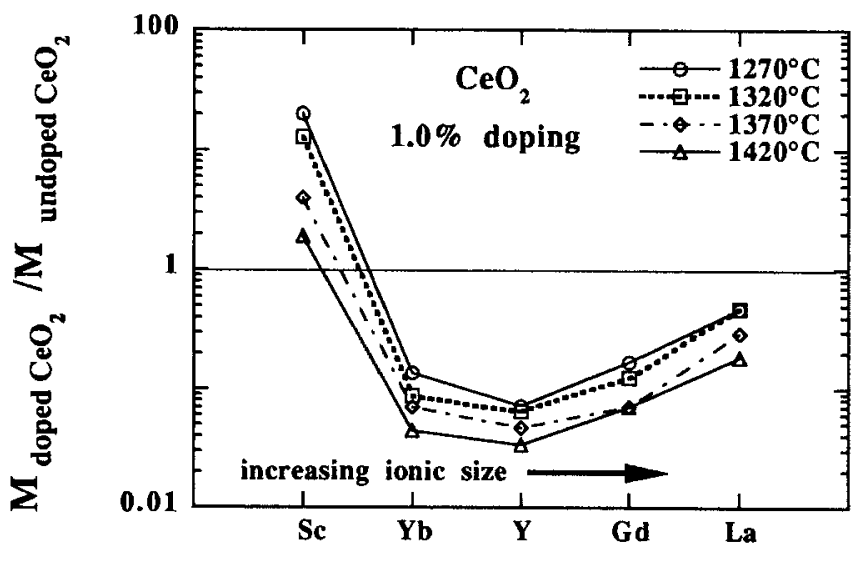

Dopant

Fig. 9. Normalized grain boundary mobilities of $1.0 \%$-doped $\mathrm{CeO}_{2}$. Dopants ordered by ionic radii.

(One other combination, $0.5 \% \mathrm{La}+0.5 \% \mathrm{Y}$, also shown in Fig. 11, has a mobility closer to that of $1 \% \mathrm{La}$.)

\section{(6) Grain Boundary Segregation}

Direct evidence for solute segregation at the grain boundary was sought in the sample containing $1.0 \% \mathrm{Y}$. This specimen was sintered at $1270^{\circ} \mathrm{C}$ for $1.2 \mathrm{~h}$ and could be intergranularly fractured at room temperature. The ESCA spectrum obtained for the as-fractured surface is shown in Fig. 12 (top), having a strong electron emission peak identified as $3 d$ electron for $\mathrm{Y}$. The intensity of this peak diminished after $30 \mathrm{~min} \mathrm{Ar}$ ion sputtering, which removed surface (grain boundary) atoms, as also shown in Fig. 12 (bottom). Strong segregation of dopant cation is thus verified in this case.

\section{Discussion}

\section{(1) Undoped $\mathrm{CeO}_{2}$ Mechanism of Cation Diffusion}

Our experiment with oxygen partial pressure clearly demonstrates that an increase in $\left[\mathrm{Ce}^{3+}\right]$ or $\left[V_{0}\right]$ also increases grain boundary mobility. This rules out the possibility of solute drag by $\mathrm{Ce}^{3+}$. Such an effect is not expected anyway, for the following reason. $\mathrm{Ce}^{3+}$ can readily exchange an electron with $\mathrm{Ce}^{4+}$ to effect the $\mathrm{Ce}^{3+} / \mathrm{Ce}^{4+}$ conversion, via the so-called "small polaron" mechanism, which is known to have a very small activation energy $(0.21 \mathrm{eV})$ in the present system. ${ }^{6}$ Thus, $\mathrm{Ce}^{3+}$ movements are not essentially distinguishable kinetically from 


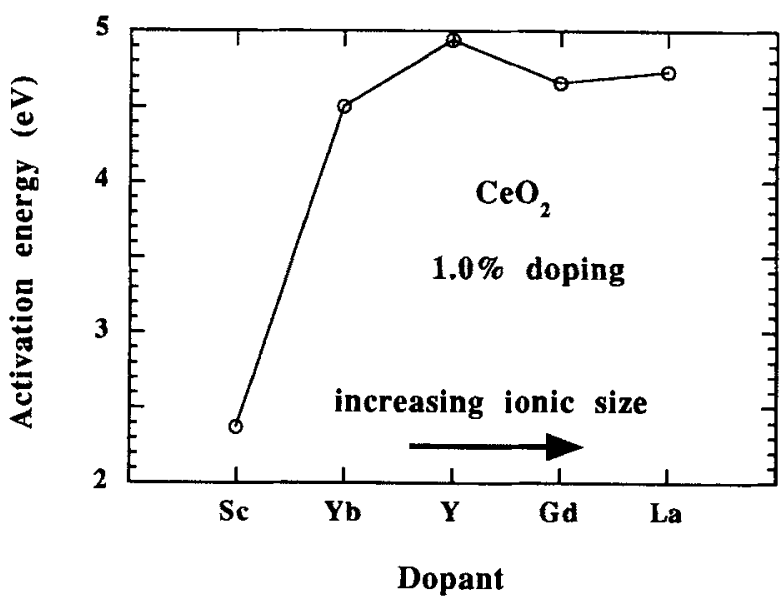

Fig. 10. Activation energy of mobility of 1.0\%-doped $\mathrm{CeO}_{2}$. Dopants ordered by ionic radii.

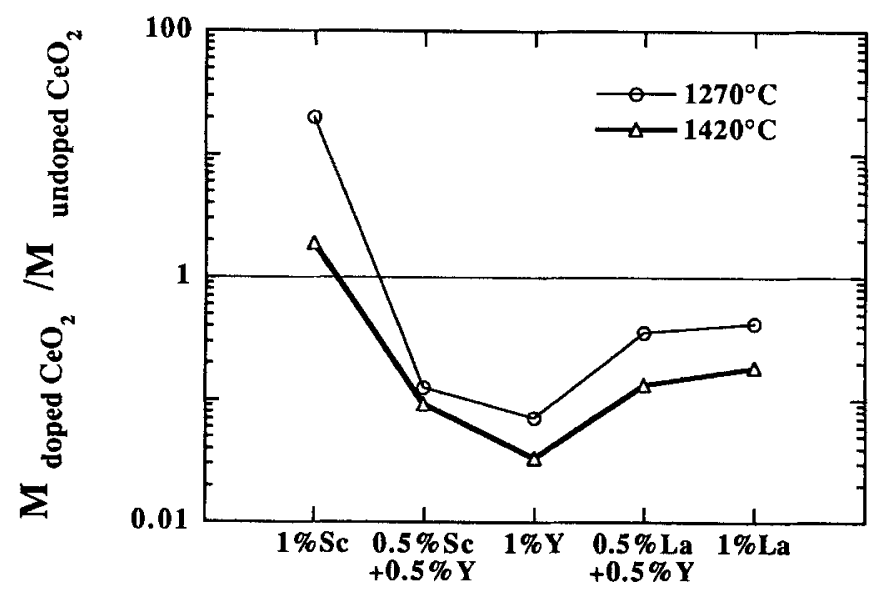

Fig. 11. Normalized grain boundary mobilities of $\mathrm{CeO}_{2}$ with single and double dopants ( $1.0 \%$ total).

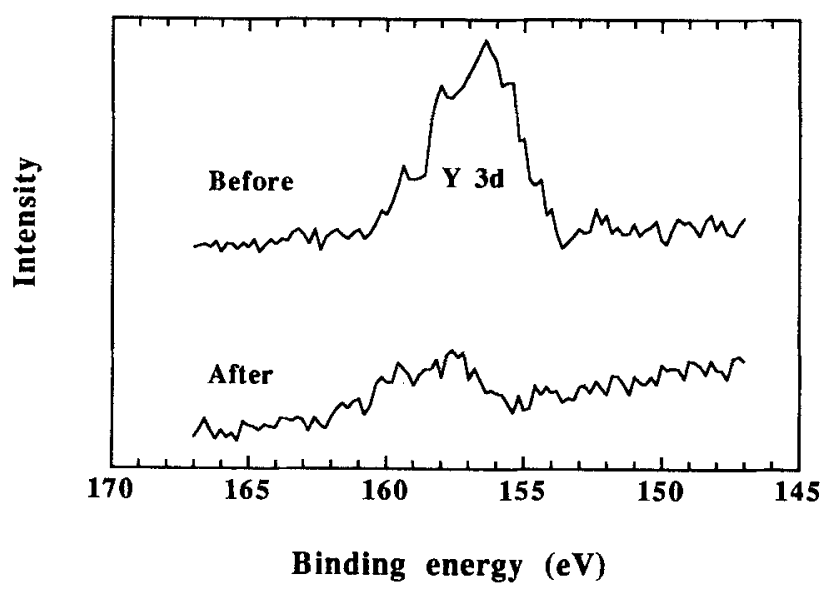

Fig. 12. ESCA spectra of intergranularly fractured $1.0 \%-\mathrm{Y}$ doped $\mathrm{CeO}_{2}$ before and after argon ion sputtering.

$\mathrm{Ce}^{4+}$ movements. (The high small-polaron mobility also implies that $\mathrm{Ce}^{3+}-V_{0}$ association is either weak or infrequent, since the activation energy of $V_{0}$ migration is $0.87 \mathrm{eV},{ }^{16}$ much higher than $0.21 \mathrm{eV}$ quoted above for electronic transport.) Therefore, the higher grain boundary mobility at reduced oxygen partial pressure is not related to $\left[\mathrm{Ce}^{3+}\right]$ but to $\left[V_{0}\right]$. That is, a high concentration of oxygen vacancies can enhance cation diffusion. This is most likely due to an increased concentration of cation interstitials in the presence of abundant oxygen vacancies. (The other possible cation diffusion mechanism requires a higher $\left[V_{\mathrm{Ce}}\right]$, which is ruled out in view of the Schottky defect reaction, giving $\left[V_{\mathrm{Ce}}\right] \propto\left[V_{\mathrm{o}}\right]^{-2}$ and hence suppressing cation diffusion.) In addition, lacking any reason for solute drag, we believe that in undoped $\mathrm{CeO}_{2}$, grain boundary mobility is controlled by grain boundary diffusion of $\mathrm{Ce}$.

The above picture finds support in the literature of $\mathrm{UO}_{2-x}$ for which cation (lattice) diffusivity increases with $x{ }^{16}$ This has been interpreted by Matzke ${ }^{17}$ as an indication of an interstitial mechanism. By considering the following defect reactions along with charge balance

Oxygen dissolution:

$$
\mathrm{O}_{2}+4 \mathrm{Ce}_{\mathrm{Ce}}^{\prime}+2 \mathrm{~V}_{\mathrm{o}} \stackrel{\Delta H_{\mathrm{o}}}{\longleftrightarrow} 4 \mathrm{Ce}_{\mathrm{Ce}}+2 \mathrm{O}_{\mathrm{O}}
$$

Schottky defect formation:

$$
\text { null } \stackrel{\Delta C_{\mathrm{s}}}{\longleftrightarrow} V_{\mathrm{Ce}}^{\prime \prime \prime}+2 V_{\mathrm{o}}
$$

Frenkel defect formation:

$$
\text { null } \stackrel{\Delta G_{\Gamma}}{\longleftrightarrow} V_{\mathrm{Ce}}^{\prime \prime \prime \prime}+\mathrm{Ce}_{\mathrm{j}}^{\cdots \cdot \cdot}
$$

we find

$$
\begin{aligned}
{\left[V_{\mathrm{o}}\right]=} & K_{\mathrm{O}_{2}}^{\prime} \exp \left(\frac{-\Delta H_{\mathrm{O}_{2}}}{6 k T}\right) \\
{\left[V_{\mathrm{Ce}}^{\prime \prime \prime \prime}\right]=} & \left(\frac{K_{\mathrm{S}}^{\prime}}{{K^{\prime}{ }_{\mathrm{O}_{2}}{ }^{2}}^{\prime \prime}}\right) \exp \left(-\frac{\left(\Delta G_{\mathrm{S}}-\Delta H_{\mathrm{O}_{2}} / 3\right)}{k T}\right) \propto\left[V_{\mathrm{o}}^{*}\right]^{-2} \\
{\left[\mathrm{Ce}_{\mathrm{i}}^{\cdots \cdots \cdot}\right]=} & \left(\frac{K_{\mathrm{F}}^{\prime} K_{\mathrm{O}_{2}}^{\prime 2}}{K_{\mathrm{S}}^{\prime}}\right) \\
& \exp \left(-\frac{\left(\Delta G_{\mathrm{F}}-\Delta G_{\mathrm{S}}+\Delta H_{\mathrm{O}_{2}} / 3\right)}{k T}\right) \propto\left[V_{\mathrm{o}}^{*}\right]^{2}
\end{aligned}
$$

In the above, $K$ 's are preexponential constants for defect reactions, $\Delta H$ and $\Delta G$ 's are enthalpy and Gibbs free energies, respectively, for such reactions. (Note that $K_{\mathrm{O}_{2}}^{\prime} \propto P_{\mathrm{O}_{2}}{ }^{-1 / 6}$, but for brevity, the partial pressure dependence is not expressed explicitly in Eqs. (5-7) or below.) Thus, by assuming the interstitial mechanism for cation diffusion, and by assuming the grain boundary mobility to be proportional to cation diffusivity, we expect the grain boundary mobility to have the following form:

$$
\begin{aligned}
M= & M_{\mathrm{o}} \exp \left(-\frac{\left(\Delta G_{\mathrm{F}}-\Delta G_{\mathrm{s}}+\Delta H_{\mathrm{O}_{2}} / 3+\Delta H_{\mathrm{i}}^{\mathrm{m}}\right)}{k T}\right) \\
& \propto\left[V_{\mathrm{o}}^{*}\right]^{2}
\end{aligned}
$$

where $\Delta H_{\mathrm{i}}^{\mathrm{m}}$ is the migration energy of $\mathrm{Ce}_{\mathrm{i}}$.

Strictly speaking, a quantitative evaluation of the above model requires knowledge of $\Delta G_{\mathrm{F}}, \Delta G_{\mathrm{S}}, \Delta H_{\mathrm{O}}$ and $\Delta H_{\mathrm{i}}^{\mathrm{m}}$ in the grain boundary. This information is not available, however. Therefore, we will use the values of bulk (lattice) reactions in the following discussion. From Ref. 18, we obtain $\Delta H_{\mathrm{O}_{2}} \sim$ $9 \mathrm{eV}$. Subtracting $\Delta H_{\mathrm{O}_{2}} / 3$ from the activation energy of grain boundary mobility in undoped $\mathrm{CeO}_{2}, \sim 6 \mathrm{eV}$, we find $\Delta G_{\mathrm{F}}-\Delta G_{\mathrm{S}}+\Delta H_{\mathrm{i}}^{\mathrm{m}} \sim 3 \mathrm{eV}$. This value for the combination of defect formation and migration energies is compared with its counterpart in $\mathrm{UO}_{2-x}, \sim 5 \mathrm{eV}{ }^{19}$ The difference could be due to either different materials or different diffusion paths. (The data of $\mathrm{UO}_{2-x}$ are for lattice defect diffusion.) Another prediction is a $P_{\mathrm{O}_{2}}^{-1 / 3}$ dependence for grain boundary mobility. As we stated 
before, the precise $P_{0}$, dependence was not established in this study because of inadequate time for establishing equilibrium $P_{\mathrm{O}_{2}}$ in the grain growth experiments. The difference between the apparent dependence, $P_{\mathrm{O}_{2}}^{-1 / 4.8}$ and the one predicted could thus be attributed to the above cause.

\section{(2) Intrinsic Regime (0.1\% Dopants)}

In the intrinsic regime, especially at lower temperatures, normalized grain boundary mobility is enhanced by $\mathrm{Y}$ and $\mathrm{Gd}$, and suppressed by $\mathrm{Sc}, \mathrm{Yb}$, and La. These trivalent dopants are known to generate charge-compensating oxygen vacancies with which the association energy increases with the size misfit and becomes especially large for $\mathrm{Sc}^{7}$ Following the proposal that oxygen vacancies enhance cation migration, we interpret the higher normalized mobility with $\mathrm{Y}$ and Gd doping as evidence of increased free oxygen vacancies provided by these dopants, assuming the grain boundary mobility in this case is still controlled by $\mathrm{Ce}$ interstitial. This effect is most pronounced at lower temperatures, presumably because of the lower concentration of oxygen vacancies in undoped $\mathrm{CeO}_{2}$ that is reflected in the ratio of $M_{\text {doped CeO }} / M_{\text {undoped } \mathrm{CeO}_{2}}$. On the other hand, the suppression effect of undersized dopants implies, in this interpretation, a decrease of free oxygen vacancies in the material. According to the literature, ${ }^{7} \mathrm{Sc}$ dopants not only are associated with their own oxygen vacancies, but also can scavenge oxygen vacancies from other trivalent cations. This is because only one oxygen vacancy is created by every two trivalent dopants, so that $\mathrm{Sc}-V_{\mathrm{o}}$ association is available to only half of the Sc cations if the latter are distributed randomly. The other half of Sc are then capable of association with additional oxygen vacancies generated from other sources. This scavenging effect is expected to deplete the free oxygen vacancies (due to $\mathrm{Ce}^{3+}$ ) which otherwise could facilitate Ce diffusion. Thus, the suppression effect is also consistent with our proposal. ( $\mathrm{Yb}$ is an undersized dopant which presumably behaves like Sc, although the scavenging effect has not been reported in the literature.) The case of La is probably an intermediate one with little net contribution to the free $V_{o}$ concentration and, hence, Ce diffusion. La is known to have a somewhat stronger tendency to associate with $V_{\mathrm{o}}$ than $\mathrm{Y}$ and $\mathrm{Gd}$, but this tendency is much weaker than that of Sc.

The above picture is now quantified by considering the trivalent dopant, $\mathrm{D}^{3+}$, as a potential trapping center for oxygen vacancies, with a binding energy $B$. This serves to reduce the concentration of oxygen vacancies in the bulk $\left[V_{0}\right]_{\text {free }}$, thereby affecting $\left[V_{\mathrm{Cc}}\right]$ and $\left[\mathrm{Ce}_{i}\right]$ through Schottky and Frenkel defect reactions. The probability of having a trapped site occupied is given by the Fermi-Dirac statistics ${ }^{20}$

$$
p=\frac{1}{1+\frac{1-\left[V_{\mathrm{o}}\right]}{\left[V_{\mathrm{o}}\right]} e^{-B / k T}}
$$

As $B>>k T$ (strong binding), $p \longrightarrow 1$, and as $B<<k T$ (weak binding), $p \rightarrow\left[V_{\mathrm{O}}\right] e^{B / k T}$, which reverts to the Boltzmann statistics. Furthermore, each dopant may be able to trap either one or two oxygen vacancies. (In the latter case, the coordination number of dopant cation is reduced to six, which might be reasonably expected for undersized dopants.) Therefore, in the following treatment, we allow a multiplicity factor, $m$, which is the number of trapping sites per trapping center. In doped $\mathrm{CeO}_{2}$, the total number of oxygen vacancies is given by

$$
\left[V_{\mathrm{o}}\right]=\left[V_{\mathrm{o}}\right]_{\text {thermal }}+\frac{1}{2}\left[D^{3+}\right]=\frac{1}{2}\left(\left[\mathrm{Ce}^{3+}\right]+\left[\mathrm{D}^{3+}\right]\right)
$$

where $\left[V_{\mathrm{o}}\right]_{\text {thermal }}$, as given by Fig. 1, is attributed to $\left[\mathrm{Ce}^{3+}\right]$. The concentration of free oxygen vacancies available for Frenkel and Schottky defect reactions is then

$$
\left[V_{\mathrm{o}}\right]_{\text {free }}=\left[V_{\mathrm{o}}\right]-m p\left[D^{3+}\right]
$$

In the limit of weak trapping, $B<<k T, p \rightarrow\left[V_{\mathrm{O}}\right] \sim 0$, as in the case of $\mathrm{Y}$ and Gd doping, we obtain $\left[V_{\mathrm{o}}\right]_{\text {free }}=\left[V_{\mathrm{o}}\right]_{\text {thermal }}+$
$\frac{1}{2}\left[D^{3+}\right]$, which is larger than $\left[V_{\mathrm{o}}\right]_{\text {thermal }}$ in the undoped $\mathrm{CeO}_{2}$. In the other limit of strong trapping, $B>>k T, p \rightarrow 1$, as in the case of Sc doping, we obtain $\left[V_{\mathrm{O}}\right]_{\text {free }}=\left[V_{\mathrm{O}}\right]_{\text {thermal }}-$ $\left(m p-\frac{1}{2}\right)\left[D^{3+}\right]$, which is always less than $\left[V_{o}\right]_{\text {thermal }}$ in the undoped $\mathrm{CeO}_{2}$.

The above results are illustrated in Fig. 13 in an Arrhenius plot for $\left[V_{0}\right]_{\text {free }}$ for several binding energies $\left(\left[D^{3+}\right]=0.1 \%\right)$. Here, $\left[V_{\mathrm{O}}\right]_{\text {thermat }}$ is taken from Fig. 1 , and $m=2$ is assumed. (For $m=1$, the trend is similar but less pronounced.) It is clear that, compared to undoped $\mathrm{CeO}_{2}$, the concentration of free oxygen vacancies is increased by trivalent dopants in the case of weak bonding (the limiting case being $p=0$ ), and vice versa in the case of strong bonding (the limiting case being $p=1$ ). It is also clear that the apparent activation energy for $\left[V_{\mathrm{o}}\right]_{\text {free }}$ is lower in the case of weak binding and higher in the case of strong binding. Recall that the concentration of diffusing species, $\left[\mathrm{Ce}_{\mathrm{i}}\right]$, is proportional to $\left[V_{0}\right]_{\text {froc }}^{2}$. The results in Fig. 13 imply that the Ce diffusion is enhanced, but with a lower activation energy, by trivalent dopants of a small binding energy for oxygen vacancy as in the case of $\mathrm{Y}$ and $\mathrm{Gd}$, and vice versa for trivalent dopants of a large binding energy ( $\mathrm{Sc}$ and $\mathrm{Yb}$ ). These predictions are in accord with our experimental data shown in Figs. 7 and 8 .

The normalized mobility can be expressed by comparing $\left[\mathrm{Ce}_{\mathrm{i}}\right]$, i.e.

$$
\tilde{M}=\frac{\left[V_{\mathrm{o}}\right]_{\text {free }}^{2}}{\left[V_{\mathrm{o}}\right]_{\text {thermal }}^{2}}=\left(1+\left(\frac{1}{2}-m p\right)\left[D^{3+}\right] /\left[V_{\mathrm{o}}\right]_{\text {thermal }}\right)^{2}
$$

using the data of $\left[V_{\mathrm{o}}\right]_{\text {thermal }}$ from Fig. 1, and the binding energies obtained from (lattice) oxygen conductivity of 1.0\%-doped $\mathrm{CeO}_{2}$. $(B$ in eV: $\mathrm{La}=0.14, \mathrm{Gd}=0.12, \mathrm{y}=0.21, \mathrm{Sc}=0.67$, not available for $\mathrm{Yb}^{7}$ ) We have plotted the predicted normalized mobility as a function of temperature for several $0.1 \%$ doped $\mathrm{CeO}_{2}$ in Fig. 14. The trend predicted is similar to that found in Fig. 7, but the enhancement effect for $\mathrm{Y}$ and $\mathrm{Gd}$ is not as pronounced (off by a factor of two) and the value of La doping is slightly overestimated. This would imply that the concentration of free oxygen vacancies in undoped $\mathrm{CeO}_{2}$ is less than that in Fig. 1, and that the binding energy between La and oxygen vacancies is higher than previously reported.

\section{(3) Extrinsic Regime (1.0\% Dopants)}

In the extrinsic regime, we evidence suppressed grain boundary mobility with the exception of Sc doping. Direct evidence of solute segregation at the grain boundary indicates that solute drag could be operating. In such a case, a solute cloud develops around the grain boundary whose mobility is now controlled by

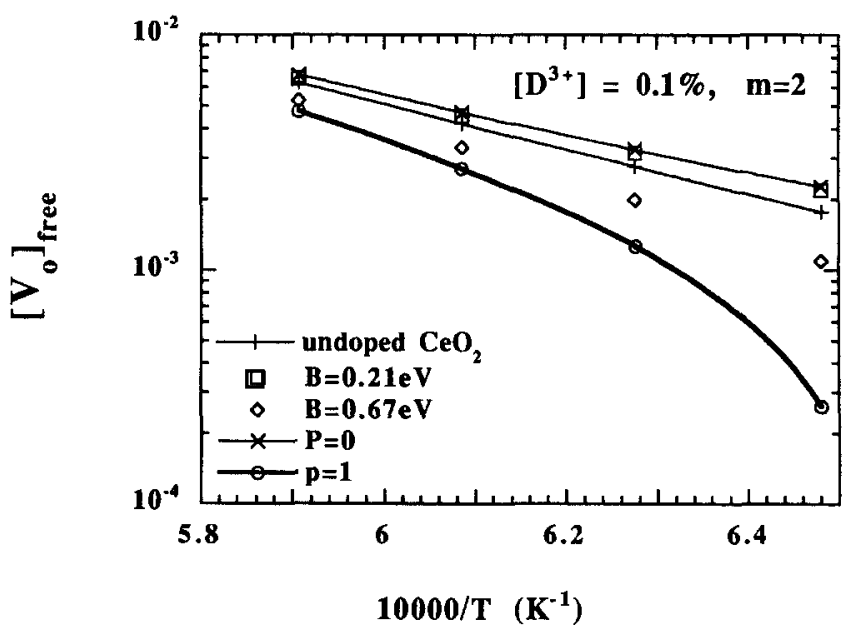

Fig. 13. Arrhenius plot for $\left[V_{\mathrm{O}}\right]_{\text {free }}$, assuming dopants of various dopant-oxygen vacancy binding energies. (Data for undoped $\mathrm{CeO}_{2}$ from Ref. 5.) Limiting cases are given by $p=0$ and $p=1$. 


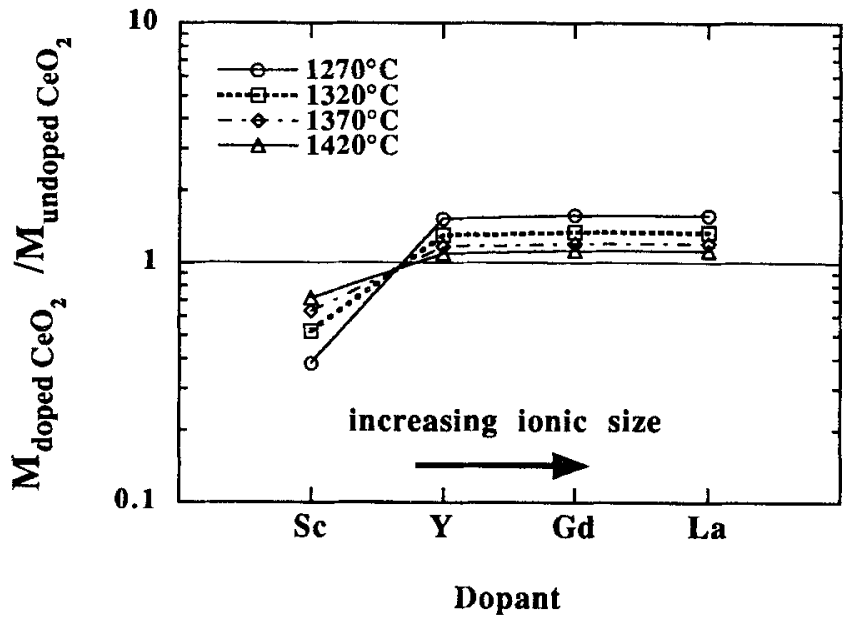

Fig. 14. Predicted normalized grain boundary mobility for several $0.1 \%$-doped $\mathrm{CeO}_{2}$ calculated from Eq. (12). ( $m=2$ is assumed.)

the lattice diffusion of these solutes. Accepting the same proposal that oxygen vacancies enhance cation diffusion, we expect those dopants least associated with the oxygen vacancies, $Y$ and $G d$ in particular, to have the lowest diffusivity themselves and, hence, to effect the lowest grain boundary mobility. (In essence, we envision a local equilibrium at the dopant between associated oxygen vacancies, cation vacancies, and cation interstitials, the latter being the rate-controlling species.) This suppression effect on normalized mobility is most pronounced at higher temperatures, because of the relatively strong temperature dependence of the intrinsic grain boundary mobility in undoped ceria that lowers the ratio of $M_{\text {cloped CeO}_{2}} /$ $M_{\text {undepes } \mathrm{CeO}_{2}}$ at high temperatures. This strong temperature dependence seen in Fig. 4 partly reflects the temperature dependence of $\left[V_{O}\right]$ in the undoped material, in contrast to the extrinsic regime in which $\left[V_{\mathrm{o}}\right]$ is largely fixed and independent of temperature.

The above consideration can also be quantified following the defect relations described previously. Except for Sc, weak binding is assumed to be obeyed to explore the temperature dependence of mobility. In such a case, $\left[V_{\mathrm{o}}\right]_{\text {total }} \approx \frac{1}{2}\left[D^{3+}\right]$. The dopant lattice diffusion is further assumed to follow the same cation interstitial mechanism. In analogy to Eq. (8), we can then derive

$\mathscr{D}_{\text {solute }}=\mathscr{D}_{\text {solute }}^{\mathrm{O}} \exp \left(-\frac{\left(\Delta G_{\mathrm{F}}-\Delta G_{\mathrm{S}}+\Delta H_{\mathrm{i}}^{\mathrm{m}^{\prime}}\right)}{k T}\right) \times\left[D^{3+}\right]^{2}$

for the diffusivity of dopant, $\mathscr{D}_{\text {solute }}$, where $\Delta H_{\mathrm{i}}^{\mathrm{m}}$ is the lattice migration energy for dopant interstitials. (No $P_{\mathrm{O}_{2}}$ dependence is expected in this case.) According to the classical solute drag theory of elastic interaction between solute and grain boundary, ${ }^{21-23} M \propto D_{\text {solute }} /\left[D^{3+}\right]$. For charged solute, ${ }^{24}$ the space charge theory predicts a weaker concentration dependence but retains the diffusivity dependence, $M \propto \mathscr{D}_{\text {solute }} /\left[D^{3+}\right]^{1 / 2}$. Thus, in both cases, the grain boundary mobility is expected to follow the same temperature dependence as Eq. (13). According to Fig. 10, the activation energy for mobility in $1.0 \%$-doped $\mathrm{CeO}_{2}$ is around $4.5 \mathrm{eV}$ for all the dopants except Sc. This compares with Eq. (8) and Fig. 6 for $M$ in undoped $\mathrm{CeO}_{2}$, which has an activation energy $\Delta G_{\mathrm{F}}-\Delta G_{\mathrm{S}}+\Delta H_{\mathrm{O}_{2}} / 3+\Delta H_{\mathrm{i}}^{\mathrm{m}}=6 \mathrm{eV}$. The smaller activation energy and $\Delta H_{\mathrm{O}_{2}}=9 \mathrm{eV}$ then imply that $\Delta H_{\mathrm{i}}^{\mathrm{m}}-\Delta H_{\mathrm{i}}^{\mathrm{m}} \approx 1.5 \mathrm{eV}$, i.e., a higher migration energy is required for lattice diffusion than for grain boundary diffusion. The relative insensitivity of this value to the type of dopants could suggest a similar migration energy for all the dopants.

Sc doping presents a very different case. Among all the trivalent dopants, Sc is the only one that enhances grain boundary mobility at $1.0 \%$ concentration, implying the loss of solute drag in this case. Yet codoping by $0.5 \% \mathrm{Sc}$ and $0.5 \% \mathrm{Y}$ almost entirely restores the solute drag expected (i.e., one-half of that if $1 \% \mathrm{Y})$. As mentioned previously, Sc shows a strong oxygen vacancy scavenging effect trapping at least one oxygen vacancy at each Sc cation. Thus, with Sc doping only, there are not enough oxygen vacancies to be associated with Sc, whereas with Sc and Y codoping, every Sc is provided with one oxygen vacancy. Since the latter configuration apparently lowers grain boundary mobility, it suggests that grossly undersized trivalent dopants without $V_{O}$ association are highly unstable in the fluorite structure, are capable of high mobility, and may further induce high mobility of the host cations. Direct spectroscopic evidence, which indicates a severe lattice distortion around an undersized dopant in fluorite-structured oxides, has been recently observed by extended $\mathrm{X}$-ray absorption fine structure (EXAFS) in $\mathrm{ZrO}_{2}{ }^{25}$ and $\mathrm{CeO}_{2} \cdot{ }^{10}$ It has also been previously implicated by the anomalous low-temperature dielectric and anelastic relaxation peaks observed in $\mathrm{Sc}$-doped $\mathrm{CeO}_{2}{ }^{26,27}$ Accepting this body of evidence, we are not surprised to see a large enhancement effect of Sc on diffusion, especially at low temperatures, when a thermal activation for migration is otherwise sluggish.

Lastly, when $0.5 \% \mathrm{Y}$ and $0.5 \% \mathrm{La}$ are present together, it appears that there is some increase in La diffusivity, due to the availability of oxygen vacancies afforded by $Y$. This causes the mobility in the codoped material to approach that of $1 \% \mathrm{La}$ in Fig. 11. The above interpretation can again be rationalized by the different tendency for vacancy association.

\section{(4) Implications of Interstitial Mechanism}

Diffusion studies of fluorite-structured oxides are most complete in the $\mathrm{UO}_{2}$ system. Although the mechanism for cation diffusion in hyperstoichiometric $\mathrm{UO}_{2+x}$, via cation vacancy, has been generally accepted, the mechanism in hypostoichiometric $\mathrm{UO}_{2-x}$ is still controversial. (Since pure $\mathrm{UO}_{2 \ldots x}$ is more difficult to prepare, the following general picture is drawn on the basis of both pure $\mathrm{UO}_{2-x}$ and its solid solutions with $\mathrm{PuO}_{2}$ and $\mathrm{CaO}$ for which the hypostoichiometric composition can be more readily stabilized.) Based on the observation that self-diffusivity of $\mathrm{U}$ increases with $x$ at $x>0.02$ in $\mathrm{UO}_{2-x}$, Matzke ${ }^{17}$ proposed an interstitial mechanism. The controversy arises because (i) there has never been any structural evidence of cation interstitials in $\mathrm{UO}_{2}$ or $\mathrm{CeO}_{2}$, and (ii) theoretical calculations have routinely predicted a very large difference between formation energy of cation Frenkel defect, and Schottky defect, $\Delta G_{\mathrm{F}}-$ $\Delta G_{\mathrm{S}} \sim 10 \mathrm{eV},{ }^{28}$ which fails to account for the much smaller activation energy observed in $\mathrm{UO}_{2-x}(\sim 5 \mathrm{eV}) .{ }^{19}$ Nevertheless, $\mathrm{U}$ diffusion data in $\mathrm{UO}_{2-x}$ have been consistently supported by other experiments, such as self-diffusivity, ${ }^{29}$ creep, and evaporation ${ }^{29}$ in $\mathrm{U}_{1-y} \mathrm{Pu}_{y} \mathrm{O}_{2-x},{ }^{30,31}$ as well as grain growth in $\mathrm{U}_{1-x} \mathrm{Ca}_{y} \mathrm{O}_{2-x}{ }^{32}$ We further note that $\mathrm{Ca}$ has been shown to assume interstitial sites in cubic $\mathrm{ZrO}_{2}$ at high temperatures $\left(1800^{\circ} \mathrm{C}\right),{ }^{33}$ and, at any rate, only a very small concentration of cation interstitials (below the detection limit of most structural study techniques) is required to dominate diffusion by virtue of their very low migration energy. Therefore, the experimental evidence is clearly in favor of the interstitial mechanism. This argument now receives additional support from our study of $\mathrm{CeO}_{2-x}$.

Cation diffusion in fluorite-structured oxides is depicted schematically by Fig. 15. Here the oxygen ions are in simple cubic arrangement and cations are in one-half of the cubiccenter sites. It can be shown from this figure that the interstitial site, denoted as I in Fig. 15, is always involved in cation diffusion. In the case of the vacancy mechanism, the jump of the cation can follow either [1 10] direction in one step or proceed along $[100]+[010]$ directions in two steps. Although the first path is shorter in jump distance, it must go through the saddle point which is located at the edge center between two oxygen ions and is severely constricted. In contrast, the second path, while longer, passes through the much less constricted saddle point located at the face center between four oxygen ions. Thus, 


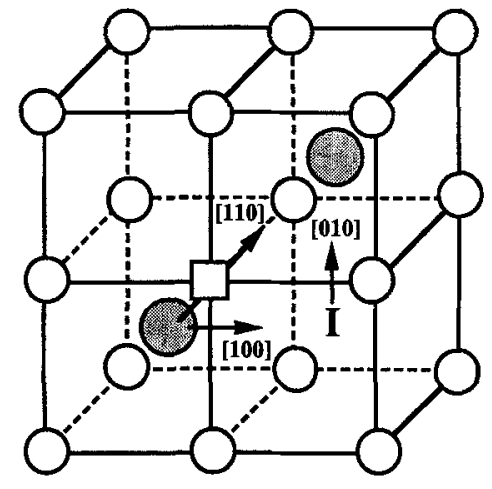

$\bigcirc$ Oxygen
$\square$ Cation
$\square$ Oxygen vacancy

\section{Interstitial}

Fig. 15. Fluorite structure illustrating possible cation jump paths (a) path 1: [110], (b) path 2: $[100]+[010]$.

the second path, via the intermediate state at the interstitial site, is probably favored. This mechanism is believed to operate in hyperstoichiometric compositions $\left(\mathrm{UO}_{2+x}\right)$. In the hypostoichiometric compositions $\left(\mathrm{UO}_{2-x}\right.$ and $\left.\mathrm{CeO}_{2-x}\right)$, on the other hand, the population of $V_{\mathrm{Ce}}$ is much lower. This allows the interstitial $\mathrm{Ce}_{\mathrm{i}}$, located at the I site in Fig. 15, to become the dominant diffusing species itself. Note that in the above picture the actual atomic movement is essentially the same whether it is the "vacancy" mechanism or the interstitial mechanism.

The above considerations could be generally applicable for fluorite-structured oxides. Although the diffusivity data are scarce in this area, several studies in diffusion-related phenomena appear to be consistent with our picture of the cation interstitial mechanism. In cubic $\mathrm{Bi}_{2} \mathrm{O}_{3}$, with a defective fluorite structure, Fung et al ${ }^{34}$ recently reported kinetics for an interface-controlled diffusive transformation which shows a suppression effect of $\mathrm{Zr}$ dopant and an enhancement effect of $\mathrm{Ca}$ and $\mathrm{Sr}$ dopants. This can be rationalized on the premise that cation interstitials are the dominant diffusing species in cubic $\mathrm{Bi}_{2} \mathrm{O}_{3}$. Observation of a higher grain boundary mobility, accompanied by a lower activation energy, at higher $\left[V_{0}\right]$ has also been reported in zirconia ceramics. ${ }^{3}$ Although this case is complicated by a phase change (tetragonal phase at low oxygen vacancy concentrations and cubic phase at high oxygen vacancy concentrations), the essential trend remains the same.

Finally, we summarize all the data of grain boundary mobility reported thus far for zirconia and ceria by our laboratory. In Fig. 16, we plot the data of several zirconia from Ref. 3 and ceria from the present study, Here $8 \mathrm{Y}-\mathrm{CSZ}$ is a cubic zirconia containing 8 mol\% $\mathrm{Y}_{2} \mathrm{O}_{3}, 12 \mathrm{Ce}-\mathrm{TZP}$ is tetragonal $\mathrm{Zr}_{0.88} \mathrm{Ce}_{0.12} \mathrm{O}_{2}$, and $2 \mathrm{Y}$-TZP is tetragonal zirconia containing $2 \mathrm{~mol} \% \mathrm{Y}_{2} \mathrm{O}_{3}$ (i.e., $3.92 \% \mathrm{Y}$ ). It can be seen that at $1.0 \%$-Y doping, the grain boundary mobility of $\mathrm{CeO}_{2}$ and $12 \mathrm{Ce}-\mathrm{TZP}$ is of the same order of magnitude, but $2 \mathrm{Y}$-TZP with a higher dopant concentration has a substantially lower mobility. It is also clear that the effect of $1 \% \mathrm{Sc}$ is truly anomalous, and that the activation energy of grain boundary mobility in undoped $\mathrm{CeO}_{2}$ is unusually high.

\section{Conclusions}

(1) Grain boundary mobility of $\mathrm{CeO}_{2}$ is proposed to be controlled by cation diffusivity through an interstitial mechanism. At low dopant concentrations (intrinsic regime), grain boundary diffusion of the host cation is dominant, whereas at high dopant concentrations (extrinsic regime), dopant diffusivity in the lattice is dominant.

(2) The effect of trivalent dopants is closely related to their ability to provide charge-compensating oxygen vacancies and their interaction with oxygen vacancies. Through Frenkel and Schottky reactions, these vacancies determine the concentration of cation interstitials, which in turn determine cation diffusivity and, hence, grain boundary mobility.

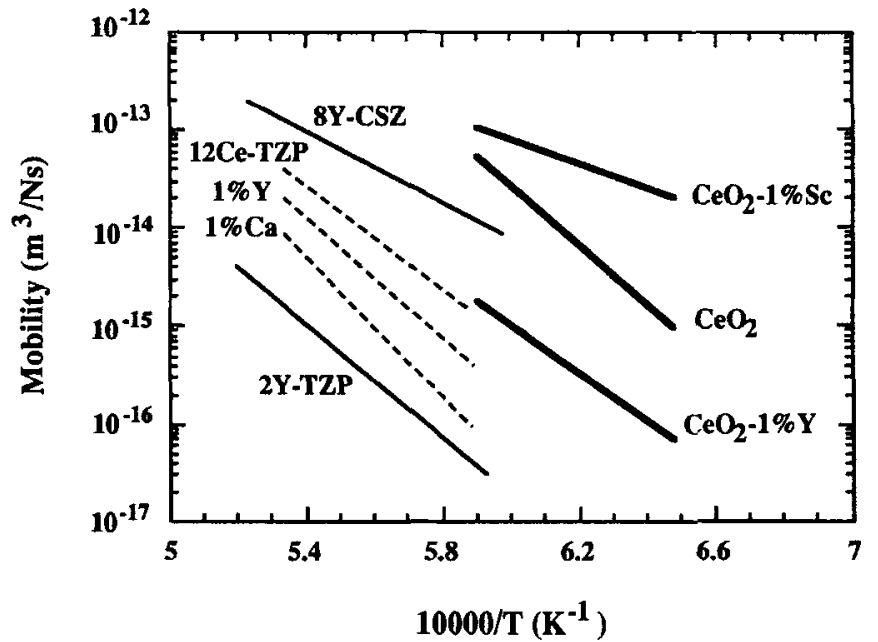

Fig. 16. Grain boundary mobility of ceria and zirconia solid solutions.

(3) In the intrinsic regime, dopants ( $\mathrm{Y}$ and $\mathrm{Gd}$ ) that provide free oxygen vacancies to the host cations enhance grain boundary mobility, while dopants that scavenge oxygen vacancies ( $\mathrm{Sc}$ and $\mathrm{Yb}$ ) depress grain boundary mobility. A simple model that relates grain boundary mobility to concentration of free oxygen vacancies is proposed to rationalize these observations.

(4) In the extrinsic regime, the dopant (Y) that is least associated with oxygen vacancies suppresses grain boundary mobility the most. Bare Sc unassociated with any oxygen vacancy enhances grain boundary mobility anomalously.

(5) Cation migration via an interstitial mechanism is suggested to be a general mechanism that dominates diffusive processes in oxygen-deficient fluorite-structured oxides such as (hypostoichiometric) $\mathrm{CeO}_{2 \cdots x}, \mathrm{ZrO}_{2-x}, \mathrm{UO}_{2-x}$, and cubic $\mathrm{Bi}_{2} \mathrm{O}_{3}$.

\section{References}

"I-W. Chen, "Mobility Control of Ceramic Grain Boundaries and Interfaces," Mater. Sci. Eng., A, 166, 51-58 (1993).

${ }^{2}$ R. K. Roy and R. L. Coble, "Solubilities of Magnesia, Titania, and Magnesium Titanate in Aluminum Oxide," J. Am. Ceram. Soc., 51 [1] 1-6(1968).

${ }^{3}$ S. L. Hwang and l-W. Chen, "Grain Size Control of Tetragonal Zirconia Polycrystals Using the Space Charge Concept," J.Am. Ceram. Soc., 73 [11] $3269-77(1990)$.

${ }^{4}$ I. K. Naik and T. Y. Tien, "Electrical Conduction in $\mathrm{Nb}_{2} \mathrm{O}_{5}$-Doped Cerium Dioxide," J. Electrochem. Soc., 126 [4] 562-66 (1979).

II. K. Naik, "Electrical Properties, Nonstoichiometry and Defect Structures of Pure and Niobium Pentoxide-Doped Cerium Dioxide"; Ph.D. Thesis. University of Michigan, Ann Arbor, MI, 1976.

${ }^{6}$ I. K. Naik and T. Y. Tien, "Small-Polaron Mobility in Nonstoichiometric Cerium Dioxide," J. Phys. Chem. Solids, 38 [3] 311-15 (1978).

${ }^{7} \mathrm{R}$. Gerhardt and A. S. Nowick, "Ionic Conductivity of $\mathrm{CeO}_{2}$ with Trivalent Dopants of Different Ionic Radii," Solid State Ionics, 5, 547-50 (1981).

${ }^{8}$ V. Butler, C. R. A. Catlow, B. E. F. Fender, and J. H. Harding, "Dopant Ion Radius and Ionic Conductivity in Cerium Dioxide," Solid State Ionics, 8, 109 13 (1983).

${ }^{9}$ P. L. Chen and I-W. Chen, "Reactive Cerium (IV) Oxide Powders by the Homogeneous Precipitation Method," J.Am. Ceram. Soc., 7 [6] 1577-83 (1993).

I"P. Lin, I-W. Chen, J. E. Penner-Hahn, and T. Y. Tien, "X-ray Absorption Studies of Ceria with Trivalent Dopants," J. Am. Ceram. Soc., 74 [5] 958-67 (1991).

${ }^{11}$ H. H. Moebius, H. Witzmann, and F. Zimmer, "Rontgenographische Untersuchungen an Fluoritphasen in den System des Scandiumoxides mit Zirkon-, Cer- und Thoriumdioxid," Z. Chem., 4, 194-95 (1964).

${ }^{12}$ T. H. Etsell and S. N. Flengas, "The Electrical Properties of Solid Oxide Electrolytes," Chem. Rev., 70 [3] 339-76 (1970).

${ }^{13}$ J. D. McCullough and J. D. Britton, "X-ray Studies of Rare Earth Oxide System. II. The Oxide Systems $\mathrm{Ce}^{\mathrm{IV}}-\mathrm{Sm}^{\mathrm{II}}, \mathrm{Ce}^{\mathrm{IV}}-\mathrm{Gd}^{\mathrm{III}}, \mathrm{Ce}^{\mathrm{IV}}-\mathrm{Y}^{\mathrm{III}}, \mathrm{Pr}^{\mathrm{IV}}-\mathrm{Y}^{\mathrm{III}}$, and $\operatorname{Pr}^{\mathrm{rlI}}-\mathrm{Y}^{\mathrm{ItI},}, \mathrm{J}$. Am. Chem. Soc., 74, 5225-27 (1952).

${ }^{14}$ R. D. Shannon, "Revised Effective Ionic Radii and Systematic Studies of Interatomic Distances, Halides and Chalcogenides," Acta Crystallogr., Sect. A, Found. Crystallogr., 32, 756 (1976).

${ }^{15}$ R. L. Fullman, "Measurement of Particle Size in Opaque Bodies," Trans. AIME, 1970 [3] 447-52 (1953).

"B. C. H. Steele and J. H. Floyd, "The Oxygen Self-Diffusion and Electrical Transport Properties of Non-stoichiometric Ceria and Ceria Solid Solutions," Proc. Br. Ceram. Soc., 19, 55-76 (1971). 
${ }^{17}$ H. Matzke, "Lattice Disorder and Metal Self-Diffusion in Non-stoichiometric $\mathrm{UO}_{2}$ and $(\mathrm{U}, \mathrm{Pu}) \mathrm{O}_{2}, "$ J.Phys. (Paris) Suppl., 34 [11-12] C9-317-C9-325 (1973).

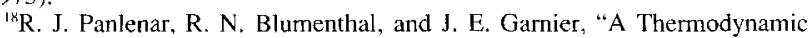
Study of Nonstoichiometric Cerium Dioxide," J. Phys. Chem. Solids, 36 [11] 1213-22(1975)

${ }^{14} \mathrm{H}$. Matzke, "Diffusion in Nonstoichiometric Oxide"; in Nonstoichiometric Oxides. Edited by O. T. Sorensen. Academic Press, New York, 1991

${ }^{21} \mathrm{~J}, \mathrm{P}$. Hirth and J. Lothe, Theory of Dislocations; pp. 510-11. Wiley, New York, 1982

"J. W. Cahn, "The Impurity Drag Effect in Grain Boundary Motion," Acta Metall., 10 [9] 789-98 (1962).

"K. Lucke and H. P. Stuwe, "On the Theory of Impurity Controlled Grain Boundary Motion," Acta Metall, 19 [10] 1087-99 (1971).

${ }_{23}$ D. J. Srolovitz, R. Eykholt, D. M. Bavnett, and J. P. Hirth, "Moving Discommensuration Interacting with Diffusing Impurities," Phys. Rev, B: Condens Matter, 35 [12] 6107-21 (1987).

${ }^{24} \mathrm{I}-\mathrm{W}$. Chen, "Solute Drag on Grain Boundary in Ionic Solids--The Space Charge Effect"; pp. 254-67, in Grain Boundary Controlled Properties of Fine Ceramics. Edited by K. Ishizaki, K. Niihara, M. Isotani, and R. G. Ford. Elsevier Applied Science, London, U.K., 1992.

${ }_{25} \mathrm{I}-\mathrm{W}$. Chen, P. Li, and J. E. Penner-Hahn, "Atomic: Structure Studies of Zirconia Solid Solutions by EXAFS"; pp. 27-38 in Applications of Synchrotron Radiation Techniques to Materials Science, Vol. 307, MRS Symposium Proceedings Series. Edited by D. Perry, N. D. Shinn, R. L. Stockbauer,
K. L D'Amicoamd, and L. J. Terminello. Materials Research Society, Pittsburgh, PA, 1991.

${ }^{26}$ R. Gerhardt-Anderson, F. Zamani-Noor, and A. S. Nowick, "Study of $\mathrm{Sc}_{2} \mathrm{O}_{3}$ Doped Ceria by Anelastic Relaxation," Solid State Ionics, 9-10, 931-36 (1983).

${ }^{27} \mathrm{R}$. Gerhardt, W. K. Lee, and A. S. Nowick, "Anelastic and Dielectric Relaxation of Scandia-Doped Ceria," J. Phys. Chem. Solids, 48 [6] 563-69 (1987).

${ }^{28}$ C. R. A. Catlow, "Point Defeet and Electronic Properties of Uranium Oxide," Proc. R. Soc. London, A, 353, 533-61 (1977).

${ }^{29} \mathrm{M}$. H. Rand and T. L. Markin, "Some Thermodynamic Aspects of (U, Pu)O Solid Solutions and Their Use as Nuclear Fuels"; pp. 637-50 in Thermodynamics of Nuclear Materials. International Atomic Energy Agency, Vienna, Austria, 1967.

${ }^{30} \mathrm{~B}$. Burton, "Prediction of Creep Behavior from Diffusion Data in $\mathrm{UO}_{2}$ Nuclear Fuel"; pp. 415-35 in Thermodynamics of Nuclear Materials, Vol. I. International Atomic Energy Agency, Vienna, Austria, 1974.

${ }^{3}$ J. L. Routbort, N. A. Jared, and J. C. Voglewede, "Compressive Creep of Mixed-Oxide Fuel Pellets," J. Nucl. Mater., 44, 247-59 (1972).

${ }^{32}$ J. R. MacEuan and J. Hayashi, "Grain Growth in UO, III. Some Factors Influencing Equiaxed Grain Growth," Proc. Br. Ceram. Soc., 7, 245-72 (1967).

${ }^{33}$ A. M. Diness and R. Roy, "Experimental Confirnation of Major Change of Defect Type with Temperature and Composition in Ionic Soljds." Solid State Commun., 3, 123-25 (1965).

${ }^{34}$ K. Z. Fung, A. V. Virkar, and D. L. Drobeck, "Massive Transformation in the $\mathrm{Y}_{2} \mathrm{O}_{3}-\mathrm{Bi}_{2} \mathrm{O}_{3}$ System," submitted to I. Am. Ceram. Soc., 1993. 